\title{
Cholesteryl N-Monomethoxypoly(ethylene glycol)-succinate-L-phenylalanine: Synthesis and Effect on Liposomes
}

\author{
Won Young Yang, Sang-Hee Lee, Eunok Lee, ${ }^{\ddagger}$ Guk Hoon Chung, ${ }^{\ddagger}$ and Youn-Sik Lee \\ School of Chemical Engineering and Technology, The Research Institute of Industrial Technologv: \\ Chonbut National Lnversitw, Chonju 561-756, Korea \\ Department of Chemistry, Kunsan National Lniversity, Kunsan, 573-360, Korea \\ ¿Bio-Chem BG. Biotech., 39-3, Songbok-Ri, Suji-Eup, Yougin-City, Kionggi-Do, Korea \\ Recerved September 11, 2001
}

\begin{abstract}
Poly(ethylene glycol)-phosphatidylethanolamine conjugate (PEG-PE) has been used in preparing longcirculating liposomes. As a substitute for PEG-PE which can also be used in the long-circulating liposome formualtions. but can be prepared more readily with a lower cost. PEG-Phe-Chol was synthesized from PEG. phenylalanine, and cholesterol. The addition of the PEG derivative to distearoylphosphatidylcholine (DSPC) led to the formation of mixed micelles as well as liposomes when the derivative content was $10 \mathrm{~mol} \%$ or greater. On the other hand the addition of just $5 \mathrm{~mol} \%$ PEG-Phe-Chol to dioleoylphosphatidylethanolamine (DOPE) generated mixed micelles as well as liposomes. but the formation of mixed micelles was completely inhibited by the addition of cholesterol. The leakage of entrapped calcein out of DOPE/cholesterol (7/3) liposomes containing $5 \mathrm{~mol} \%$ PEG-Phe-Chol was about $45 \%$ during the incubation time for 24 h in $50 \%$ rabbit plasma. which was similar to that of the same liposomes containing $5 \mathrm{~mol} \% \mathrm{PEG}$-dipalmitoylphosphatidylethanolamine (DPPE) under the identical conditions.
\end{abstract}

Keywords : Poly(etly lene glycol). Phenylalanine, Cholesterol. Mixed micelle. Long-circulating liposome.

\section{Introduction}

Many types of liposome-based products have been extensively studied for effective drug delivery systemss. ${ }^{l}$ However. the liposomal drug delivery to cells or tissues other than the reticulo-endothelial system (RES) was difficult since liposomes are rapidly taken up by the RES cells in the liver and spleen. ${ }^{23}$ To overcome this problem, ganglioside $G_{M 1}$ was incorporated into liposomes. Therapeutic applications of $\mathrm{G}_{\mathrm{M} 1 \text { - }}$ containing liposomes, however, are not practical due to the high cost of $\mathrm{G}_{\mathrm{M} 1}$ and the difficulty in obtaining large quantities either by extraction of natural sources or by synthesis.

Monomethoxypoly (ethylene glycol)-phosphatidylethanolamine congjugate (PEG-PE) was also reported to prolong the circulation lifetime of liposomes. ${ }^{+}$The linkage between $P E G$ and PE can be variable as shown in Figure 1 where dipalmitoylphosphatidylethanolamine (DPPE) was employed as one of the common PEs. ${ }^{5}$ The PEG protective action may be due to the flexibility of polymer molecules and the ability to form a dense polymeric cloud over the liposome surface ${ }^{67}$ However, even though PEG-PE can be prepared in large quantities compared to $\mathrm{G}_{\mathrm{M}}$. its preparation is still costly since $\mathrm{PE}$ is expensive.

The PEG-cholesterol (PEG-Chol) and PEG-dipalmitoylglycerol (PEG-DPG) conjugates were also synthesized by coupling monomethoxypoly (ethylene glycol) with either cholesterol or dipalmitoylglycerol via an ether bond. ${ }^{8}$ The concentrations of the circulating liposomes containing PEG-

*To whom all comespondence should be addressed e-mail: yosklearachechonbuk.ac.kr
Chol or PEG-DPG in mice blood were relatively high at $2 \mathrm{~h}$ post-injection, but much lower at $24 \mathrm{~h}$ post-injection compared to those containing $\mathrm{G}_{\mathrm{M} / 1}$ or PEG-distearoylphosphatidylethanolamine. The shorter circulating lifetimes were attributed to the lack of effective long-lasting association of those compounds with the liposomes.

We synthesized a PEG derivative of cholesterol, PEGPhe-Chol. Cholesterol was chosen as a lipid part since it has been frequently used in preparing stable liposomes. Phenylalanine was used as an another spacer in addition to the succinate. The Phe spacer provides an amide bond which may form a hydrogen bond with phospholipid molecules and enhance the retention time of the derivative in liposomes. Furthemore, the phenyl group allows one to monitor conveniently any further reaction and separation by thin layer cluromatograply since any compounds containing aromatic rings or polyconjugated moiety are easily detected with a UV lamp. The PEG with number-average molecular weight of 2000 was used since it has been most commonly employed in the long-circulating liposome formulations. Of course, all the starting materials are neither relatively toxic nor expensive. This paper describes the synthesis of the PEG derivative and its effects on liposome stability in vitro.

\section{Experimental Section}

Synthesis of PEG-Phe-Chol. A solution of $\mathrm{N}$-(tentbutoxycarbonyl)-L-phenylalanine $(0.200 \mathrm{~g}, 0.754 \mathrm{mmole})$, cholesterol $(0.350 \mathrm{~g}, 0.905 \mathrm{mmole})$, diisopropylcarbodiimide (DIPC. 0.155 g. 0.980 mmole) and N.N-dimethylaminopyridinium $p$-toluenesulfonate (DPTS. 0.235 g. 0.754 
mnole) in dichloromethane $(5 \mathrm{~mL})$ was stirred for $3 \mathrm{~h}$ at roon temperature. The reaction mixture was diluted with hexane $(10 \mathrm{~mL})$ and the resulting solid was filtered off. The filtrate was concentrated and the residue was clurontatographed (silica gel, hexane/ethyl acetate $=10: 1$ ) to give $0.445 \mathrm{~g}$ of a white solid. The solid was dissolved in dichloromethane/trifluoroacetic acid $(2 / \mathrm{l} . \mathrm{v} / \mathrm{v})$ and stirred for $30 \mathrm{~min}$ at room temperature. The reaction mixture was basified with aqueous sodium carbonate solution. extracted with diclloromethane. dried over sodium sulfate. and concentrated to get $0.367 \mathrm{~g}$ of cholesteryl ester of L-phenylalanine which was used in the next step without further purification (91\%).

A solution of cholesteryl ester of L-phenylalanine (0.149 g, 0.28 numole) and N-hydroxysuccininidyl monomethoxypoly (ethylene glycol) succinate $(0.531 \mathrm{~g}, 0.24$ mumole) in dichloromethane $(5 \mathrm{~mL})$ was stirred for $12 \mathrm{~h}$ at roon temperature. The reaction mixture was washed with aqueous sodium carbonate solution, concentrated. and cluromatographed (ethyl acetate/methanol $=10: 1$ and then dichloromethane/ methanol $=10: 1$ ). The crude product was finally purified with recrystallization from hexane/dichloromethane to obtain pure PEG-Phe-Chol $(0.589 \mathrm{~g} .94 \%)$.

Preparation of Liposomes. 1,2-Distearoylphosphatidylcholine (DSPC) or a mixture of DSPC and either PEGDPPE or PEG-Phe-Chol in chloroform was dried with a rotary evaporator under a reduced pressure. The dried lipid films were vacuun desiccated for $2 \mathrm{~h}$ and suspended with an aqueous calcein solution ( $25 \mathrm{mM} .300 \mathrm{mOms} / \mathrm{L}$. pH 7.5). The samples were frozen, melt. and vortexed at $50-60^{\circ} \mathrm{C}$. The freeze-thawing cycle was repeated several times. The suspensions were then sonicated at $50-60^{\circ} \mathrm{C}$ with a tip type sonicator (Misonic Inc.) for $5 \mathrm{~min}$, followed by a $10 \mathrm{~min}$ resting period. The samples were then sonicated for an additional $5 \mathrm{~min}$ and rested for $10 \mathrm{~min}$. The samples were fully sonicated for $5 \mathrm{~min}$. The liposome suspensions were chromatographed on a Bio-Gel A column equilibrated with PBS (phosphate buffered saline, $300 \mathrm{mOms} / \mathrm{L}, \mathrm{pH} 7.5$ ) to remove unentrapped calcein. Dioleoylphosphatidylethanolamine (DOPE) liposomes containing PEG-DPPE or PEGPhe-Chol were prepared as above, but the DOPE suspensions were vortexed and sonicated at room temperature. When necessary. appropriate amounts of cholesterol were added to the solutions of phospholipid and PEG-Phe-Chol in cliloroform.

Leakage Test from Liposomes in Buffer and in SerumContaining Medium. The small unilamellar DOPE liposomes $\left(1.9 \times 10^{-3} \mathrm{M}\right)$ were incubated in PBS at pH 7.5 and $37^{\circ} \mathrm{C}$. A fluorometer (Simoaminoco Luminescence Spectrometer, Series 2, excitation at $490 \mathrm{~cm}$, and emission at 520 nim) was used to measure the fluorescence intensity of calcein. and the percent leakage was calculated as described earlier. $^{9}$ For a study of plasma stability. a suspension of DOPE liposomes containing calcein $\left(3.8 \times 10^{-3} \mathrm{M}\right)$ and the same volume of rabbit plasma were preincubated at $37^{\circ} \mathrm{C}$ and mixed together. The fluorescence of the mixture was measured at different incubation time-points.

Phase Transitions of Lipid Bilayers. DSPC or a mixture of DSPC with 5 or $10 \mathrm{~mol} \%$ PEG-Phe-Chol was hydrated in PBS with the freeze-thawing procedure (about $50 \mathrm{wt} \%$ ). The hydrated sample was transferred into an aluminum DSC pan and sealed. The themmal phase transitions of the lipid bilayers were observed with a DSC 2910 differential scanning calorimeter (TA Instrument $\mathrm{Co}$.).<smiles>[Y]OC(=O)CCC(C)=O</smiles>

(a)<smiles>COC(C)(C)COC(C)C(=O)CCC(=O)NNC(Cc1ccccc1)C(=O)OC1CC[C@@]2(C)C(=CCC3C4CCC(C(C)CCCC(C)C)[C@]4(C)CCC32)C1</smiles>

(b)

Figure 1. Chemical structures of (a) PEG-DPPE and (b) PEG-Phe-Chol. 
<smiles>CC(C)CCCC(C)C1CCC2C3CC=C4CC(OC(=O)C(N)Cc5ccccc5)CCC4(C)C3CCC12C</smiles><smiles>COCCOC(=O)CCC(=O)ON1C(=O)CCC1=O</smiles>

Scheme 1. A chemical synthetic route of PEG-Phe-Chol.

\section{Results and Discussion}

$N$-(tert-Butosycarbonyl)-L-phenylalanine was coupled to cholesterol via an ester bond in the presence of DIPC and DPTS as shown in Scheme 1, and the intermediate was treated with trifluoroacetic acid in order to obtain cholesteryl ester of L-phenylalanine. N-Hydroxysuccinimidyl monomethoxypoly(ethylene glycol) succinate was synthesized from monomethoxy poly(ethylene gylcol), succinic anhydride, and N-hydroxysuccinimide according to the previously reported procedure. ${ }^{1 j}$ The funal coupling reaction of cholesteryl ester of L-phenylalanine with N-hydroxy succinimidyl monomethosypoly (ethylene glycol) produced PEGPhe-Chol as a white powder. The overall yield of the two steps from $N$-(tert-butoxycarbonyl)-L-phenylalanine was about $85 \%$. Anly side product was not detected in the final coupling reaction. The 'H-NMR spectrum of PEG-Phe-Chol showed all of the expected signals without any appreciable impurity peaks, as shown in Figure 2a. The ${ }^{13} \mathrm{C}$-NMR spectrum also shows the three characteristic carbonyl peaks at $170.6-172.5 \mathrm{ppm}$ (Figure 2b), which are corresponding to the carbon atoms of the two different ester bonds and an amide bond. Another six characteristic peaks at 122.7-139.1 ppm are corresponding to the phenyl carbon atoms and the two olefinic carbon atoms in the cholesterol moiety. Thin layer chromatography experiment revealed that there was a single component in the funal product. indicating that the isolated PEG-Phe-Chol was quite pure.

It is known that DSPC undergoes a pretransition and main transition at $51^{\circ} \mathrm{C}$ and $55^{\circ} \mathrm{C}$. respectively. ${ }^{1 \mathrm{l}} \mathrm{DSPC}$ bilayers prepared in this experiment show the pretransition at about $5 \mathrm{I}^{\circ} \mathrm{C}$ as a very small shoulder. but clearly show the main transition at $56^{\circ} \mathrm{C}$ as shown in Figure 3. DSPC bilayers containing $5 \mathrm{~mol} \%$ PEG-Phe-Chol show the main transition at $57^{\circ} \mathrm{C}$ with a shoulder at $52^{\circ} \mathrm{C}$. On the other hand, the

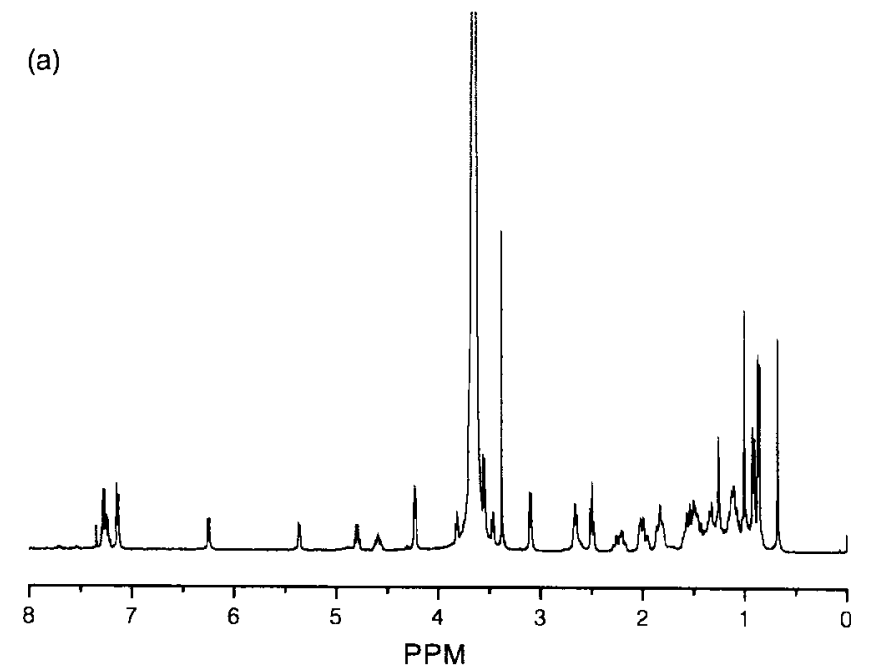

(b)
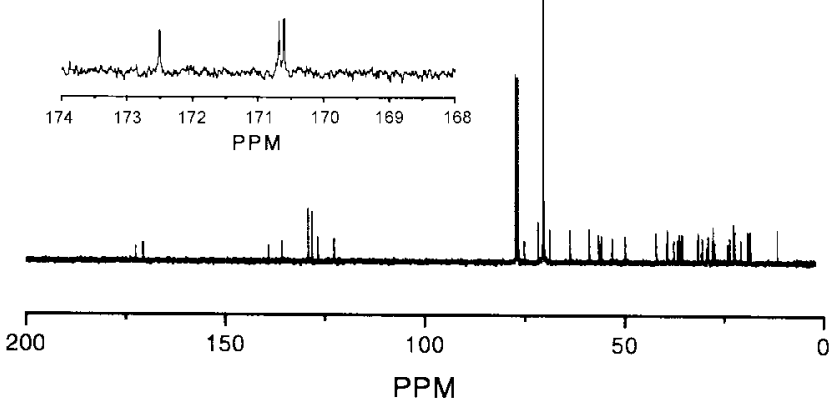

Figure 2. (a) ${ }^{1} \mathrm{H}$ and (b) ${ }^{13} \mathrm{C}$ NMR spectra of PEG-Phe-Chol in $\mathrm{CDCl}_{3}(400 \mathrm{MHz})$. 


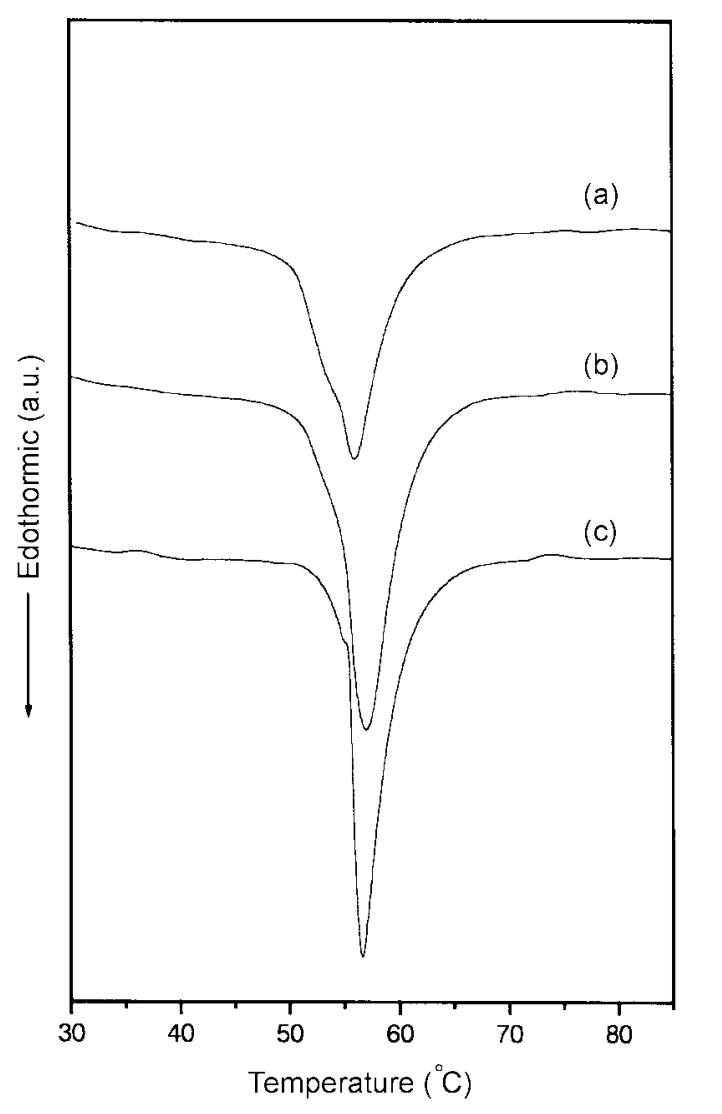

Figure 3. DSC themogranns of hydrated bilayers in PBS (about 50 wt \%) of (a) DSPC only, (b) DSPC/PEG-Phe-Chol (95/5), and (c) DSPC/PEG-Phe-Chol $(90 / 10)$. All of the themograms were obtained from the second heating scans and the scan rate was $5^{\circ} \mathrm{C} /$ minin.

main transition of DSPC bilayers containing $10 \mathrm{~mol} \% \mathrm{PEG}$ Phe-Chol appeared at $55^{\circ} \mathrm{C}$. The main transition width at the half height increased from 2.5 to $5.6^{\circ} \mathrm{C}$ as the PEG-PheChol content increased from 0 to $10 \mathrm{~mol} \%$. The enthalpy changes related to the transition peak size was not compared in this experiment since the concentrations of DSPC in the DSC samples could be different from the initial concentrations due to the procedure of sample transfer from the stocks to the DSC pans.

The pretransition is very sensitive to the presence of molecules which can interact with lipid head groups. "2 The pretransition of DSPC bilayers was shifted progressively toward a lower temperature region as the PEG-Phe-Chol content increased, indicating that PEG-Phe-Chol molecules interact with DSPC head groups. Any changes of the main transition in temperature, enthalpy. and the peak width result from a change of organization of the lipid molecules in bilayers. Thus this result indicates that PEG-Phe-Chol disturbs DSPC bilayers, and the extent of the disruption increases with the PEG-Phe-Chol content.

In order to determine the amount of PEG-Phe-Chol which can be added to DSPC or DOPE to prepare the corresponding liposomes, light-scattering measurements were performed for DSPC and DOPE dispersions prepared by the sonication method. In the case of DSPC. the size distribution
Table 1. Size distribution of lipid assemblies"

\begin{tabular}{cccl}
\hline $\begin{array}{c}\text { host } \\
\text { lipid }\end{array}$ & $\begin{array}{c}\text { PEG-Phe- } \\
\text { Chol (mol\%) }\end{array}$ & $\begin{array}{c}\text { cholesterol } \\
\text { (mol\%) }\end{array}$ & \multicolumn{1}{c}{ size distribution (nm) } \\
\hline DSPC & 0 & & $89 \pm 8(88), 300 \pm 60(12)$ \\
& 5 & & $106 \pm 9(95), 212(4), 388(1)$ \\
& 10 & & $8 \pm 1(47), 13 \pm 2(22), 100 \pm 25(31)$ \\
& 20 & & $8 \pm 1(59), 80 \pm 25(41)$ \\
& 10 & 30 & $27 \pm 3(49), 99 \pm 21(51)$ \\
DOPE & 5 & & $35 \pm 3(25), 130 \pm 25(75)$ \\
& 10 & & $47 \pm 10(48), 116 \pm 20(52)$ \\
& 20 & & $29 \pm 5(50), 120 \pm 25(50)$ \\
& 5 & 30 & $110 \pm 23(100)$ \\
& 10 & 30 & $38 \pm 6(46), 162 \pm 35(54)$ \\
\hline
\end{tabular}

In case of more than one population. the number in parenthesis indicates percentage of total population falling within theindicated size range.

was the bimodal type of small $(89 \pm 8 \mathrm{~nm})$ and large $(300 \pm 60 \mathrm{~nm})$ unilamellar liposomes as shown in Table 1 . When the PEG-Phe-Chol content was $5 \mathrm{~mol} \%$. most DSPC liposomes were in the range of $106 \pm 9 \mathrm{~nm}$. However. when the PEG-Phe-Chol content was increased to $10 \mathrm{~mol} \%$, a significant amount (about $70 \%$ ) of mixed micelles appeared. Cholesterol is known to largely affect the plyysical properties of lipid membranes. For example, the addition of cholesterol inhibited the formation of mixed micelles from liposomes of dipalnitoylphosplatidylcholine (DPPC) containing PEG$P E .^{13}$ Thus $30 \mathrm{~mol} \%$ cholesterol was added to the mixture of DSPC and $10 \mathrm{~mol} \%$ PEG-Phe-Chol, but the mixed micelles were still fomed.

On the other hand. the effect of PEG-Phe-Chol on DOPE liposomes was somewhat different from that of DSPC liposomes since a mixture of DOPE and PEG-Phe-Chol fomed mixed micelles $(25 \%)$ as well as liposomes (75\%) when the PEG-Phe-Chol content was only $5 \mathrm{~mol} \%$. However, the incorporation of $30 \mathrm{~mol} \%$ cholesterol into the mixture resulted in the fonmation of liposomes only. In other words, the fomation of mixed nicelles was completely inhibited by cholesterol. Even though the exact stabilization mechanism of the DOPE bilayers by cholesterol was not studied here. the inhibition of the liposome induction to mixed nicelles may be due to the decreased curvature at the lipid-water interface since the total volume of the hydrocarbon region should be increased by cholesterol.

DOPE does not form liposomes by itself under the plyysiological conditions. and needs a second component such as fatty acid or other types of lipid. ${ }^{1+}$ It has been frequently used along with a protonatable component in preparing $\mathrm{pH}$ sensitive liposomes which were designed to more efficiently deliver large or highly charged molecules into cells. In order to prolong circulation lifetime of the liposomes in wivo, sterically stabilized $\mathrm{pH}$-sensitive DOPE liposomes were also developed by incorporation of PEG-PE. ${ }^{13}$

The stability of DOPE/cholesterol (7/3) liposomes containing $5 \mathrm{~mol} \%$ of PEG-DPPE or PEG-Phe-Chol was studied by monitoring the leakage of entrapped calcein from the liposomes. The PEG derivative of $5 \mathrm{~mol} \%$ is known to be more than enough for protection of the small liposomes surface. ${ }^{16.17}$ 


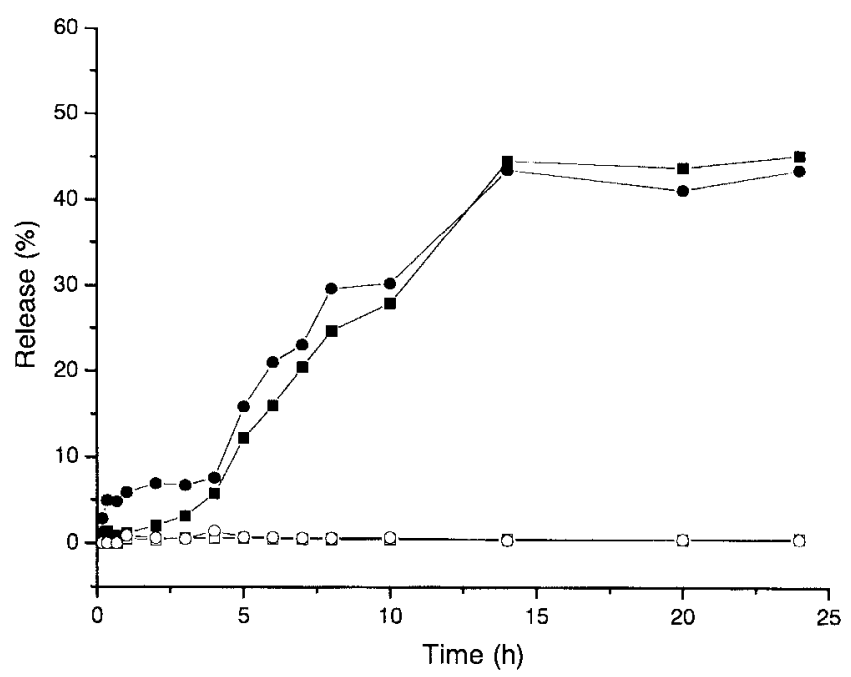

Figure 4. Percent release of entrapped calcein from DOPE/ cholesterol ( $7 / 3$ ) liposomes containing ( $) 5 \mathrm{~mol} \% \mathrm{PEG}$-DPPE or (a) PEG-Phe-Chol in 50\% rabbit plasma at $37^{\circ} \mathrm{C}$. The opened symbols represent percent release of entrapped calcein from the same liposomes, but nicubated in PBS at $37^{\circ} \mathrm{C}$.

The liposones were incubated in PBS at $37^{\circ} \mathrm{C}$ for $24 \mathrm{~h}$. but the leakages from the two different liposomes were almost negligible since the anounts of the released calcein were less than $1 \%$ in both cases. This result indicates that DOPE molecules were tightly packed in the liposomes containing $30 \mathrm{~mol} \%$ cholesterol and $5 \mathrm{~mol} \%$ PEG-Phe-Chol.

During the incubation in $50 \%$ rabbit plasma at $37^{\circ} \mathrm{C}$. however. the leakage of the entrapped calcein from the liposones increased almost linearly during the incubation for $14 \mathrm{~h}$ and reached a plateau of about $45 \%$ leakage as shown in Figure 4. If most of the PEG derivative molecules in outer monolayers of the DOPE liposomes are removed by the plasma proteins. the DOPE liposomes will be collapsed completely to release the entrapped calcein into the aqueous media. However, after the leakage for $14 \mathrm{~h}$, the DOPE liposomes in the plasnia did not release any more during the next several hours.

The leakage behavior of DOPE/cholesterol liposomes containing PEG-Phe-Chol was very similar to that of the liposomes containing PEG-DPPE. This result suggests that PEG-Phe-Chol in the DOPE liposomes may not be easily extracted out by the plasma proteins. and the degree of retention of PEG-Phe-Chol in DOPE liposomes may be similar to that of PEG-DPPE even though the retention test should be performed in wivo for further direct comparison. The anide bond in PEG-Phe-Chol may play an important role in retaining the new $\mathrm{PEG}$ derivative in the liposomes via hydrogen bonding with lipid molecules.

\section{Conclusion}

PEG-Phe-Chol was successfully synthesized from the activated PEG intermediate and cholesterol ester of Lphenylalanine. A mixture of DSPC and PEG-Phe-Chol formed liposomes only when the PEG derivative content was $5 \mathrm{~mol} \%$, but formed mixed micelles as well as liposomes when the derivative content was $10 \mathrm{~mol} \%$. DOPE formed mixed micelles as well as liposomes when the PEGPhe-Chol content was just $5 \mathrm{~mol} \%$. However. the incorporation of $30 \mathrm{~mol} \%$ cholesterol to the mixture completely inhibits the fromation of the mixed micelles. According to the DSC result. PEG-Phe-Chol destabilzes the DSPC. bilayers. resulting from the formation of the mixed micelles. The relative amount of mixed micelles depended on the content of the PEG derivative in the lipid mixtures. The leakages of entrapped calcein from DOPE/cholesterol (7/3) liposomes containing $5 \mathrm{~mol} \%$ PEG-Phe-Chol were similar to those of the DOPE/cholesterol (7/3) liposomes containing $5 \mathrm{~mol} \%$ PEG-DPPE during the incubation in PBS or $50 \%$ rabbit plasma for 24 h at 37

Acknowledgment. This work was supported by a G-7 project (1999-2000). We thank Professor Sung Zoo Kin (Department of Medicine, Chonbuk National University) for friendly providing us with the rabbit plasma.

\section{References}

1. Gregoriadis, G. TIBTECH DECEIABER 1995.13, 527.

2. Liposontes as Drig Camiers: Recent Thends and Progress. Gregoriadis. G.. Ed.: John1 Wiley and Sons: Chichester. 1988.

3. Hwang. K. I. In Liposontes: From Biophnsics to Therapettics: Ostro. M. J.. Ed.. Dekker. M.: New York. 1984; pp 109-156.

4. Mori. A.: Klibanov. A. L.; Torchilin. V. P.; Huang. L. FEBS 1991. 284. 263.

5. Parr. M. T: Ansell. S. M.: Choi. L. S.: Cullis. P. R. Biochin Biophss .Acta 1994. 1195. 21

6. Maruyana. K.: Takizawa. T.: Yuda. T.: Kennel. S. T.: Haung. L.: Iwatsuru, M. Biochin. Biophys. Acta 1995, 1234. 74.

7. Torchilin, V. P.: Papisov. M. I. J. Liposone Res. $1994,4,725$.

8. Allen. T. M.: Hansen, C.; Martin. F.: Redemann. C.; Yau-Young. A. Biochin. Biophns Acta 1991. 1066.29.

9. Jin. T. Y.: Lee. Y.-S. Bull. Korem Chen. Soc. 1998. 19.645.

10. Lee. Y.-S.: Kim. U.-J.: Lee. K.-H.: Yu. S.-C.: Lee. S. H. Bull. Korzan Chem. Soc. 1999. 20, 1085.

11. Koynova. R.: Koumanov, A.; Tenchov, B; Biochin. Bioplys. Acta 1996. 1285. 101

12. Grenier. G.: Berube. G.: Gicquaud. C.: Chent. Phamt. Bull. 1998. 46. 1480 .

13. Bedu-Addo. F. K.: Tang. P.: Xu. Y.: Huang. L. Pharmt. Res. 1996. 13. 718 .

14. Litzinger. D. C.: Huang, L. Biochim Biophys. Acta 1992. 1113 , 201.

15. Slepushkin. V. A.: Simoes. S.: Dazin. P.: Newmant. M. S.: Guo. L. S.: de Lima. M. C. P. Duzgunes. N. J. Biol. Chent 1997. 272. 2382 .

16. Torchilin, V. P.: Omelyanenko, V. G.; Papisov, M. L.: Bogdanov Jr, A. A.; Trubetskoy. V. S.: Herron. J. N.: Gentry. C. A. Biochin. Biophus. Acta 1994, 1195. 11

17. Shimada. K.: Matsuo. S.: Sadzuka. Y.: Myyagishima. A.: Nozawa. Y: Hirota. S.: Sonobe. T. Intl. J. Pham 2000. 203.255. 